\title{
Correction to: Conventional and two step sintering of PZT-PCN ceramics
}

\author{
Mostafa Keshavarzi ${ }^{1} \cdot$ Hooman Rahmani ${ }^{2} \cdot$ Ali Nemati $^{1} \cdot$ Mahdieh Hashemi $^{3}$
}

Published online: 25 January 2018

c) Springer-Verlag GmbH Germany, part of Springer Nature 2018

Correction to: Applied Physics A (2018) 124:145

$$
\text { https://doi.org/10.1007/s00339-018-1571-z }
$$

The original version of this article unfortunately contained a mistake. The presentation of Eqs. 1, 2, and 3 was incorrect. The correct versions are given below. The original article has been corrected.

$\mathrm{CoO} \stackrel{\mathrm{ZrO}_{2}}{\longrightarrow} \mathrm{Co}_{\mathrm{Zr}}^{\prime \prime}+\mathrm{O}_{\mathrm{O}}+\mathrm{V}_{\mathrm{O}}^{\circ \circ}$

$$
\mathrm{Co}_{2} \mathrm{O}_{3} \stackrel{2 \mathrm{ZrO}_{2}}{\longrightarrow} 2 \mathrm{Co}_{\mathrm{Zr}}^{\prime}+3 \mathrm{O}_{\mathrm{O}}+\mathrm{V}_{\mathrm{O}}^{\circ \circ}
$$

$$
\mathrm{Nb}_{2} \mathrm{O}_{3} \stackrel{2 \mathrm{ZrO}_{2}}{\longrightarrow} 2 \mathrm{Nb}_{\mathrm{Zr}}^{\prime}+3 \mathrm{O}_{\mathrm{O}}+\mathrm{V}_{\mathrm{O}}^{\circ \circ}
$$

The original article can be found online at https://doi.org/10.1007/ s00339-018-1571-z.

Mostafa Keshavarzi

Mostafa.Keshavarzi@alum.sharif.edu

1 Department of Materials Science and Engineering, Sharif University of Technology, Tehran, Iran

2 Department of Materials Science and Engineering, University of Texas at Arlington, Arlington, TX, USA

3 Department of Physics, College of Science, Fasa University, Fasa 74617-81189, Iran 